\title{
Research on Social Factors and Customers' Selection behavior of Small and Medium-sized E-commerce Enterprises in the Online Shopping
Environment
}

\author{
Guan-yitong ZHOU \\ School of Business/Ph.D. Candidate \\ Macau University of Science and Technology \\ Guangdong Polytechnic of Science and Technology \\ Macao, China \\ Email:grania_chou@foxmail.com
}

\begin{abstract}
The small and medium-sized e-commerce have been presented with an increasingly complex and competitive market environment, so new marketing theories are in urgent need to guide their production and management. It has great theoretical and practical significance, to rationally use all kinds of social information elements to meet customers' consumption and psychological demand in the online shopping environment. This research based on the brand community and virtual community theory, this research can provide theoretical guidance to small and medium-sized enterprises to launch online marketing. Meanwhile, by investigating the influence of online social factors on customers' purchase intention, this research can also provide a new way and management basis to enterprises to attract and retain loyal customers.
\end{abstract}

Keywords-e-commerce enterprises; Brand Knowledge; customers' purchase Intention

\section{INTRODUCTION}

Owing to benefits from the policy "mass entrepreneurship and innovation" and the rapid development of the Internet and new media, small and medium-sized e-commerce enterprises have been presented with both new development opportunities and survival challenges. In the online shopping environment, the relationship between enterprises and customers is more complex and hard to predict. Through the Internet, customers can have convenience to get a lot of information about products, services and manufacturers, thus winning more options (den Ouden, E, 2006) [5]. The positive effect of following the development trend of the Internet, continuing to maintain and develop the enterprises-and-customers relationships can help to strengthen the survivability of small and -medium-sized ecommerce enterprises. Purchasing goods through the Internet has become one of the fastest growing ways of shopping. Research has shown that e-commerce enterprises should not just focus on providing services and information, but must maintain close contacts with their customers, launch a series of communication with the customers and create an atmosphere of mutual trust, in order to improve the customer loyalty (Kim, W. G., Lee, C., \& Hiemstra, S. J. 2004)[6]. In the process of online shopping, customers use the computer and network as the media to communicate and trade with the business, so customers can not directly communicate with the sales as that in offline shopping. Owing to the lack of language, expression, action and other social information in online shopping, customers are difficult to have a sense of physical presence similar to offline shopping, which would affect their shopping experience and willingness to consume (Hassanein, K., \& Head, M. 2007)[8]. Shopping websites are the forefront for ecommerce enterprises to communicate with customers, so shopping websites play a quite important role in attracting and retaining customers. Therefore, people in the industrial and academic circle have been quite concerned about how to meticulously design shopping websites to create a good shopping atmosphere in order to bring customers the best online shopping experience (Manganari, 2009)[11]. It has great theoretical and practical significance, to rationally use all kinds of social information elements to meet customers' consumption and psychological demand in the online shopping environment. Based on the brand community and virtual community theory, this paper developed scales to form a questionnaire for data analysis. In this paper, an empirical study was made of the influence of social factors in the online environment of small and medium-sized e-commerce enterprises on customer behaviors.

\section{LITERATURE REVIEW}

\section{A. SOCIAL FACTORS IN THE ONLINE SHOPPING ENVIRONMENT}

Owing to the characteristics of Internet technology, the online environment of brand websites shows many characteristics different from the traditional market environment, such as openness, no geographical or time-space limitation, low cost of information collection, high speed and great interaction. Moreover, online brand websites mainly adopt an indirect revenue mode. Online shoppers repeatedly visit a website or choose application services of a website, mainly attracted by service contents or characteristics of the website, instead of the promotion information, price or other marketing mix. To win in the competition, the key for e- 
commerce enterprises is to strengthen the construction of their own website contents, design and provide valuable information or services, develop their own characteristics with obvious differences from their competitors, firmly attract online customers, and improve the page view and click-through rate of their websites. Therefore, research on analyzing and optimizing characteristics of online brand websites has great significance for the improvement of the page view and development of online brand websites. Characteristic elements of online brand websites include: technological ease-of-use, content usefulness, social interaction and recreation.

- Technological Ease-of-use On the basis of the view of technological ease-of-use of online websites can be defined as "the fact that online consumers do not have to put too much effort to browse websites or receive application services". To be specific, in the website design, good human-computer interaction interface, good web-page navigation design, convenience in application installation, the website-using facilitation are characteristic dimensions of the technological ease-of-use.

- Content Usefulness Online websites can provide a variety of online application services, to effectively solve many problems and improve the work performance. The content usefulness of websites can be described as the positive effect of website contents and application services on promoting the work performance or self-expression of online customers. For example, search engines, online encyclopedias and other websites or application services have provided great convenience to online consumers in information retrieval, personalized customization, e-mail use, sharing of online resources and online payment, thus greatly improving the informatization level and work efficiency in daily life. These are characteristics which have content usefulness for Internet users.

- Social Interaction In today's society, the network, which takes information technology and network technology as the basis and symbols as a medium, has become an important way of interpersonal communication. Online interaction has eliminated time, geographical and social limitations existing in traditional interaction. The subject of online social interaction is equal and free. Social interaction of online websites refers to a collection of various websites properties that enable people to make emotional, business and information exchange with the help of website functions and services .

\section{B. INFLUENCE of ONLINE SOCIAL FACtors on Customers BEHAVIOR}

At present, research on the brand community is mainly focused on its emotional and functional aspects. However, with the continuous popularization and development of the Internet, we should not ignore networking characteristics of the brand community (Deng, Z. \& Zhang, J., 2010) [3]. According to research results of $\mathrm{R}$ Gordon McDougall, online transactions have changed the behavior of customers and their future business practices. Although the huge commercial potential has driven researchers to continue to investigate the behavior of online consumers, there are still many aspects to be explored in this research field. People have recognized and agreed that the customer satisfaction is the basis for websites to build longterm relationships with customers, so the customer satisfaction is a guarantee of long-term profitability. Long-term relationships between a website and its customers begin to form, when the first transaction between the website and customers is made. However, attracting new customers is considered to be more difficult and expensive than retaining old customers. That is because the website is the most convenient media in the first transaction, so the quality of the website is the key to ensure successful transactions. Through empirical research, they have confirmed that the website easeof-use, security and privacy and interactive friendliness can affect the customer perception of the website, thus affecting the consumer's attitude towards products or services shown on the website. The online brand community takes the Internet as the main medium. The customer perception of the community is largely affected by networking characteristics of the community. Through a study of online stores, Ranaweera found that networking characteristics of online stores have a significant impact on customer purchase [12]. If network is introduced as a new dimension of the brand online community, it will be able to reflect the actual situation of the online brand community in a more comprehensive and systematic way. Therefore, in this research, characteristics of online social factors were analyzed from four dimensions: technological ease-of-use, content usefulness, social interaction, and brand community network.

\section{Regulating Effect of Brand Knowledge}

Customer characteristics, that is, personal brand knowledge, not only occupy a quite important position in the theoretical research, but also provide reference to managers in business practices. Algesheimer and other scholars found that the brand community can produce a greater impact on its members with richer brand knowledge [1]. Brand knowledge contains both customers' interest in a brand and customers' previous experience of the brand use, so customers with more knowledge about this brand are more likely to produce brand identity to the brand and its brand community. Moreover, the customers are also willing to act as a lead in brand community activities. In general, new customers of an online brand are new members of its brand community, so they are more likely to be in the process of understanding the brand and its brand community and establishing links with other members. The better customers understand a brand, the more confident the customers would be in expressing their (positive or negative) views within the community. Therefore, richer brand knowledge can help to improve customers' community identity.

\section{RESEARCH HYPOTHESES}

On the basis of literature review and qualitative research, the following research model was proposed according to the research hypotheses discussed above: 


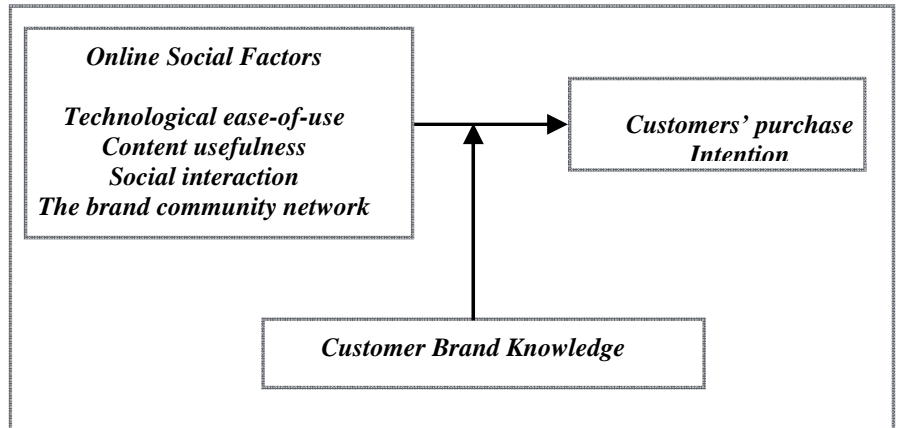

On the basis of the above analysis, following hypotheses were developed in this paper:

- H1: Technological ease-of-use in the online shopping environment has a positive influence on customers' purchase intention;

- H2: Content usefulness in the online shopping environment has a positive influence on customers' purchase intention;

- H3: Social interaction in the online shopping environment has a positive influence on customers' purchase intention;

- H4: The brand community network in the online shopping environment has a positive influence on customers' purchase intention;

- H5a: The customer brand knowledge has a positive effect on regulating the relationship between the technological ease-of-use and the customers' purchase intention in the online shopping environment;

- H5b: The customer brand knowledge has a positive effect on regulating the relationship between the content usefulness and the customers' purchase intention in the online shopping environment;

- H5c: The customer brand knowledge has a positive effect on regulating the relationship between the social interaction and the customers' purchase intention in the online shopping environment;

- H5d: The customer brand knowledge has a positive effect on regulating the relationship between the brand community network and the customers' purchase intention in the online shopping environment.

\section{RESEARCH SignificANCE AND PROPOSAL}

According to literature review, although many scholars have discussed the influence of online social factors on the customer behavior, existing studies have limitations as follows.

- Research results in this field are quite scattered. Till now, no systematic and all-around description was made of online social elements;

- There is still a lack of integrated research on the influence of online social factors on customers' purchase intention;

- Empirical research on online social factors in China is still lacking.
In this research, scales were developed to form a questionnaire. On the basis of a questionnaire survey, data was collected and analyzed. In the Internet environment, small and medium-sized e-commerce have been presented with an increasingly complex and competitive market environment, so new marketing theories are in urgent need to guide their production and management. Promoting the construction of online social factors, as a cheap and efficient marketing tool, bring a new choice to enterprises. The construction of online social factors can affect customer knowledge about products and the customer behavior, and help to rapidly convey information, understand customers' evaluation of new products and other competitive products and bring opportunities to ecommerce enterprises to communicate and cooperate with loyal customers. This research can provide theoretical guidance to small and medium-sized enterprises to launch online marketing. Meanwhile, by investigating the influence of online social factors on customers' purchase intention, this research can also provide a new way and management basis to enterprises to attract and retain loyal customers.

\section{REFERENCES}

[1] Algesheimer, R., Dholakia, U. M., \& Herrmann, A. (2005). The social influence of brand community: Evidence from european car clubs. Journal of Marketing, 69(3), 19-34.

[2] Cyr, D., Hassanein, K., Head, M., \& Ivanov, A. (2007). The role of social presence in establishing loyalty in e-service environments. Interacting with computers, 19(1), 43-56.

[3] Deng, Z., Lu, Y., Wei, K. K., \& Zhang, J. (2010). Understanding customer satisfaction and loyalty: An empirical study of mobile instant messages in China. International journal of information management, 30(4), 289-300.

[4] Dennis, C., Merrilees, B., Manganari, E. E., Siomkos, G. J., \& Vrechopoulos, A. P. (2009). Store atmosphere in web retailing. European Journal of Marketing, 43(9/10), 1140-1153.

[5] den Ouden, E., Yuan, L., Sonnemans, P. J., \& Brombacher, A. C. (2006) Quality and reliability problems from a consumer's perspective: an increasing problem overlooked by businesses? Quality and Reliability Engineering International, 22(7), 821-838.

[6] Kim, W. G., Lee, C., \& Hiemstra, S. J. (2004). Effects of an online virtual community on customer loyalty and travel product purchases. Tourism management, 25(3), 343-355

[7] Ghasemaghaei, M., Hassanein, K., \& Benbasat, I. (2014). Intention to Use Recommendation Agents for Online Shopping: The Role of Cognitive Age and Agent Complexity.

[8] Hassanein, K., \& Head, M. (2007). Manipulating perceived social presence through the web interface and its impact on attitude towards online shopping. International Journal of Human-Computer Studies, 65(8), 689-708.

[9] Ju Rebecca Yen, H., \& Gwinner, K. P. (2003). Internet retail customer loyalty: the mediating role of relational benefits. International Journal of Service Industry Management, 14(5), 483-500.

[10] Lee, S., Kim, W. G., \& Kim, H. J. (2006). The impact of co-branding on post-purchase behaviors in family restaurants. International Journal of Hospitality Management, 25(2), 245-261.

[11] Manganari, E. E., Siomkos, G. J., \& Vrechopoulos, A. P. (2009). Store atmosphere in web retailing. European Journal of Marketing, 43(9/10), 1140-1153.

[12] Ranaweera, C., McDougall, G., \& Bansal, H. (2005). A model of online customer behavior during the initial transaction: Moderating effects of customer characteristics. Marketing Theory, 5(1), 51-74.

[13] Sambrook, S., \& Roberts, C. (2005). Corporate entrepreneurship and organizational learning: A review of the literature and the development of a conceptual framework. Strategic Change, 14(3), 141.

[14] Sandberg, J. (2000). Understanding human competence at work: An interpretative approach. Academy of Management Journal, 43(1), 9-25 